\title{
Influence of equipment excitation on flexible carbody vibration of EMU
}

\author{
Huailong Shi $\cdot$ Ren Luo $\cdot$ Pingbo Wu \\ Jing Zeng $\cdot$ Jinying Guo
}

Received: 19 November 2013/Revised: 23 September 2014/Accepted: 24 September 2014/Published online: 17 October 2014

(C) The Author(s) 2014. This article is published with open access at Springerlink.com

\begin{abstract}
To study the vibration transmission characteristics of a flexible carbody and its suspended equipment, a vertical mathematical model of high-speed electric multiple unit was established with equipment excitation considered. And the dynamic unbalance and impact turbulence excitation from equipment were taken into account in a singlestage and two-stage vibration isolation system, respectively. Results show that the excitation transferred to carbody increases with suspension stiffness but decreases with the equipment mass increasing; the vibration transmission can be reduced by increasing the equipment mass or reduce the suspension stiffness. To avoid vibration resonance, the dynamic unbalance frequency of equipment should be out of the possible range of the carbody flexible modes, and a small stiffness should be applied to reduce the impact turbulence. A small stiffness, however, would result in a large movement of the equipment which is limited by the static deflection requirement, while a great stiffness will transfer high frequency vibration. Therefore, a preferred stiffness should make the suspension frequency of equipment a bit greater than the first bending mode of carbody. Additionally, a $3 \mathrm{D}$ rigid-flexible coupled dynamics model was built to verify the mathematical analysis, and they show good agreements. Results show that a two-stage isolation could reduce the excitation transmission and make the vibration of carbody and equipment acceptable.
\end{abstract}

Keywords Flexible carbody - Suspended equipment . Vibration transmission - Dynamic unbalance - Impact

H. Shi $(\bowtie) \cdot$ R. Luo $\cdot$ P. Wu $\cdot$ J. Zeng $\cdot$ J. Guo

State Key Laboratory of Traction Power, Southwest Jiaotong

University, Chengdu 610031, China

e-mail: hl_shi@126.com; shihuailong1003@126.com turbulence - Equipment excitation · High-speed electric multiple unit - Suspension stiffness · Two-stage isolation

\section{Introduction}

Vibration is normally considered as an undesirable condition; the carbody and its attached equipment can be subjected to many different forms of vibration over wide frequency ranges and acceleration levels. The damage inflicted by vibration consists of fatigue of structures and the malfunctioning of delicate equipment. Increasing the capability and life of equipment necessitates reducing the mechanical vibration of the system. The carbody vibration and riding comforts have been concerned seriously for decades $[1,2]$. With increasingly high requirement of weight-lightening design of carbody and vehicle operation speed, the vibration issue of carbody is concerned more seriously and widespread for high-speed electric multiple units (EMUs) [3, 4]. Some functional equipment, such as traction transformer, traction converter, and waste collection unit are directly suspended under the carbody chassis; some of them weigh tons and bear vibration excitation sources such as the cooling fan and mechanical switch. Almost all of them are connected to the chassis by elastic suspension elements to avoid the excitation and noise transferred to the carbody, which would deteriorate the riding comforts significantly.

Vibration isolator and dynamic vibration absorber are two conventional methods for vibration reduction besides the active control method. The former is placed between the equipment and foundation, in which the force or displacement transmission capability between equipment and foundation can be reduced. The latter is attached to a vibrating body to assist in controlling the amplitude of vibration of the system. Diana et al. [5] modeled the 
carbody as a flexible beam to study the riding comforts of passenger car and analyzed the effects of flexible vibration of carbody on the riding comforts. Young and $\mathrm{Li}$ [6] modeled the carbody as a Timoshenko beam with limited length to discuss the vehicle dynamic response to a worse track irregularity. Carlbom [7] combined the multi-body system (MBS) theory with the FEM method to analyze the vehicle dynamic response innovatively, which made it possible to consider the flexible vibration. Schandl et al. [8] used the active vibration reduction system to improve the riding comfort based on railway vehicle MBS dynamics. Foo and Goodall [9] adopted the electrohydraulic and electromagnetic actuators to reduce the carbody vibration. However, the works mentioned above only concern the system response of flexible carbody itself, and none of them involves the equipment vibration.

The dynamic vibration absorber (DVA) theory has been used to study the influence of elastic suspension of equipment on the carbody vibration, which indicates that an appropriate suspension stiffness and damping ratio could relive the first-order bending mode and reduce the flexible vibration of carbody [10-14]. Snowdon [15] achieved the vibration reduction of a cantilever beam through dynamic absorbers first and then applied the DVA theory to mechanical systems. Jacquot [16, 17] also used absorbers to reduce the vibration of plates, and he studied the damper location optimization for randomly forced cantilever beams. In $[18,19]$, in order to reduce the broad-band wave propagation and vibration within a certain frequency band, the absorbers were designed with various stiffness and damping coefficients in different types. However, the absorbers were regarded in a single-stage vibration isolation system, and the excitation from the absorber itself was not considered, such as the dynamic unbalance and impact turbulence.

In this work, in order to reduce the vibration transmission, we modeled the carbody as an Euler-Bernoulli beam to consider the flexible vibration of the carbody itself; the attached equipment under the chassis contains various exciting vibration sources, in a single-stage and two-stage vibration isolation system, respectively. The vertical motion equations of the coupled system consisting of flexible carbody and suspended equipment were derived to analyze the response of the coupled system and the influence of suspension parameters on the flexible carbody vibration. In addition, we established, a 3D rigid-flexible coupled vehicle system dynamics model by combing the MBS theory with the FEM to simulate the response of carbody and equipment to measured track excitation, and compared the simulation results with the mathematical analysis.

\section{Field test of the equipment excitation for EMU}

In order to illustrate the excitation vibration from the suspended equipment, a field test was conducted for an EMU running in the high-speed railway line from Beijing to Shanghai in China, as shown in Fig. 1. The test carbody has about five equipment with different mass and volume (Fig. 1a), and some of them carry electric motor for cooling (Fig. 1b). Also, the equipment is mounted elastically by the rubber elements to isolate the excitation from the cooling fans and to suppress the flexible vibration of carbody simultaneously (Fig. 1c). Therefore, a proper stiffness and damping coefficients of the rubber elements should be designed and verified.

The test was conducted at speed $300 \mathrm{~km} / \mathrm{h}$ on a straight line track in a good condition, and the EMU was a newly produced train with a running mileage of $80,000 \mathrm{~km}$. Both the acceleration of the carbody and equipment were measured by accelerometers with signal sampling rate $1,000 \mathrm{~Hz}$, and a $300 \mathrm{~s}$ vibration signal was recorded. Figure $2 \mathrm{a}$ depicts the schematic diagram of rubber dampers, and the accelerometers were mounted at the area belonging to the carbody and equipment, respectively, shown in Fig. 2b. The tested equipment, cooling unit, carries an exciting vibration resource driven by electrical motors.

The time history of the vibration signals is quite normal without any specialties, and the acceleration signal was analyzed using fast Fourier transform (FFT) theory. The frequency spectrum of equipment acceleration is demonstrated in Fig. 3. Obviously, there are peaks at 10, 20, 30, and $40 \mathrm{~Hz}$, and their acceleration amplitudes are much
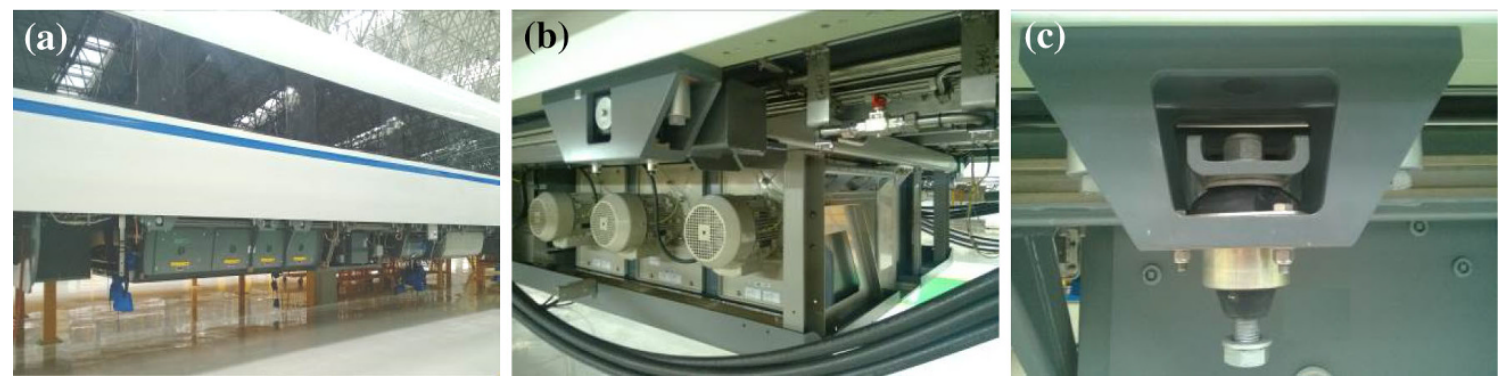

Fig. 1 The carbody of EMU: a suspended equipment under the chassis of carbody; b equipment with vibration ecitation source; $\mathbf{c}$ rubber elements applied to connect the equipment to carbody elastically 

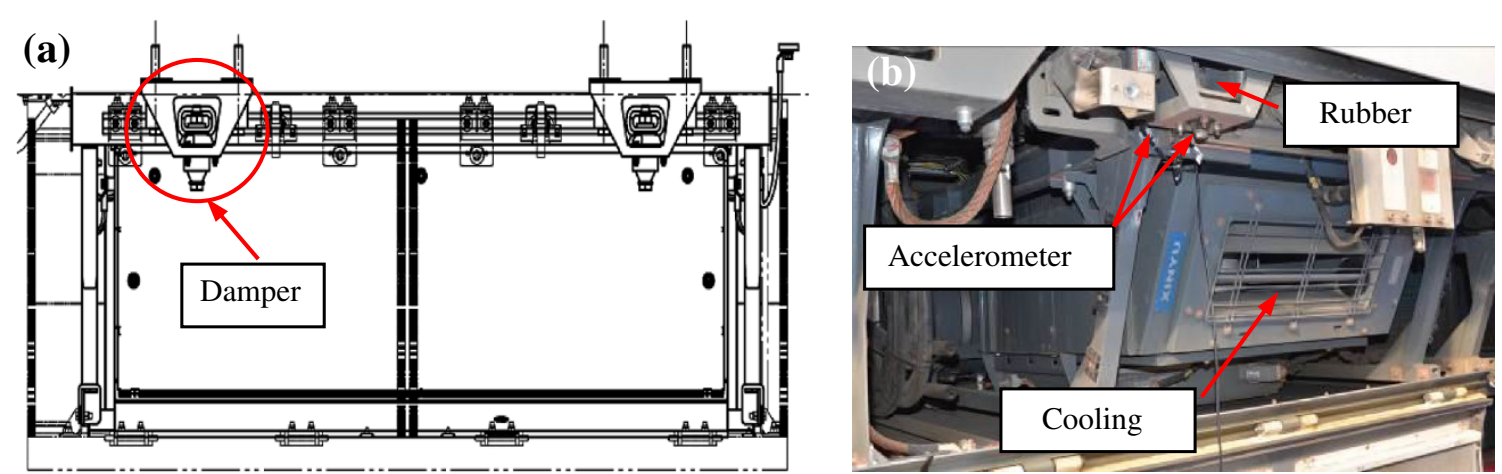

Fig. 2 Dynamic vibration test of EMU: a the elastic suspension of equipment by rubber dampers; $\mathbf{b}$ accelerometers mounted on the equipment and carbody

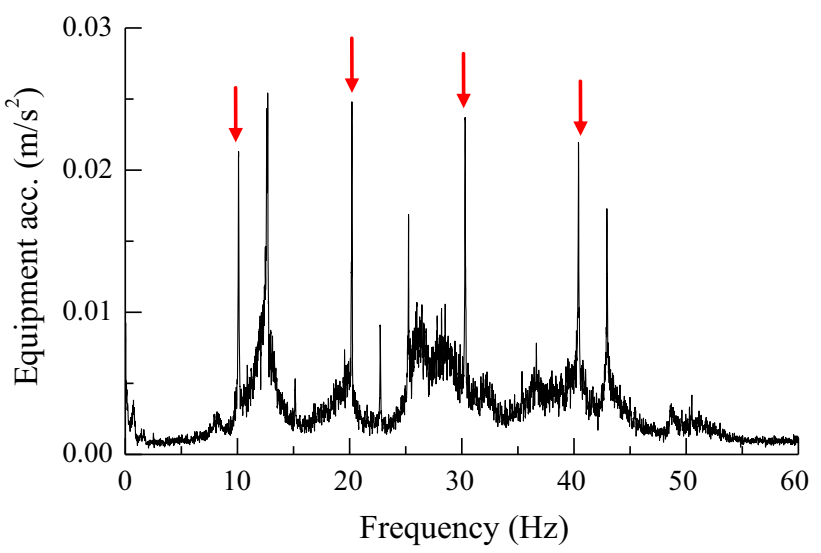

Fig. 3 The frequency spectrum of vibration acceleration of equipment

greater than the flexible vibration of carbody. Actually, this excitation was generated by the equipment with dynamic unbalance, and some of them are at the rotating frequency of the motor rotor. After cleaning the dust attached to the rotors, the vibration of the equipment returned to the normal levels. It can be concluded that no matter the rotating vibration and the dynamic unbalance, the excited vibration would be quite great, which exists in every rotation mechanical systems.

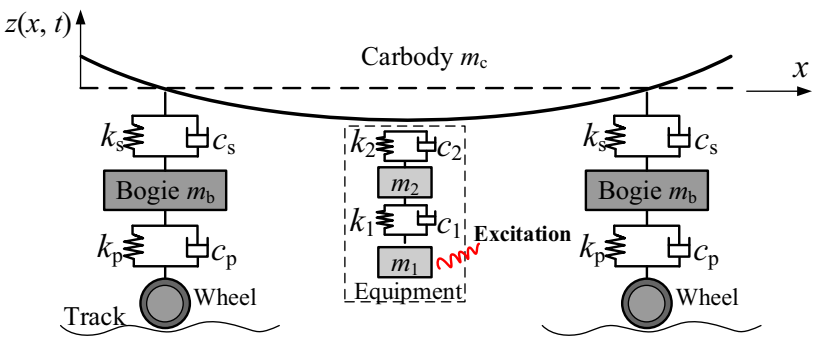

Fig. 4 Mathematical model of EMU with suspended equipment and flexible carbody

\section{Mathematical analysis}

A traditional mathematical model of an EMU with suspended equipment was set up to study the vibration characteristics of the coupled system shown in Fig. 4, which consists of a flexible carbody, two bogies, and four wheel sets, and the equipment was modeled in an single-stage vibration isolation system and two-stage vibration isolation system. Each bogie and carbody has the bouncing and pitching freedom, and it is supposed that the wheel sets are right close to rails ignoring the track elasticity. The carbody is treated as a uniform Euler-Bernoulli beam, and the coordinate system and dimensions are defined in Fig. 4.

Table 1 Parameters of vertical mathematical model

\begin{tabular}{llll}
\hline Parameters & Symbol & Parameters & Symbol \\
\hline Mass of carbody & $m_{\mathrm{c}}$ & Half of bogie centers distance & $l_{\mathrm{b}}$ \\
Carbody pitch inertia & $I_{\mathrm{c}}$ & Half of bogie wheel base & $l_{\mathrm{w}}$ \\
Mass of bogie & $m_{\mathrm{b}}$ & Length of carbody & $m_{1}$ \\
Bogie pitch inertia & $I_{\mathrm{b}}$ & Mass of equipment & $m_{2}$ \\
Secondary spring stiffness (per bogie) & $k_{\mathrm{s}}$ & Mass of equipment frame & $k_{1}$ \\
Secondary damping (per bogie) & $c_{\mathrm{s}}$ & Equipment suspension stiffness & $c_{1}$ \\
Primary spring stiffness (per axle) & $k_{\mathrm{p}}$ & Equipment suspension damping & $k_{2}$ \\
Primary damping (per axle) & $c_{\mathrm{p}}$ & Equipment frame suspension stiffness \\
Distance of equipment to carbody end & $l_{\mathrm{c}}$ & Equipment frame suspension damping & $c_{2}$ \\
\hline
\end{tabular}




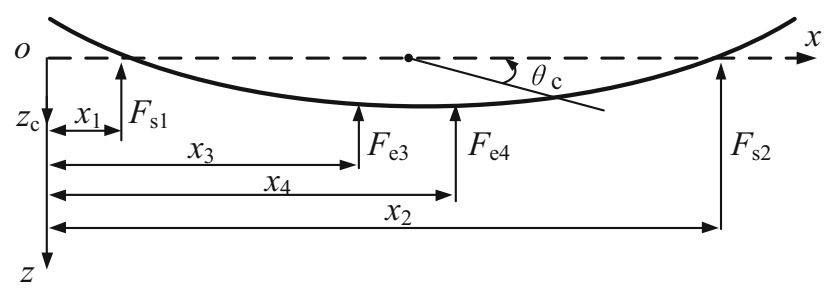

Fig. 5 The illustrations of force applied on the flexible carbody

The distance between equipment and carbody end is represented by $l_{\mathrm{c}}$. The vehicle physics parameters are listed in Table 1.

To analyze the intersection force between the equipment and flexible carbody, Fig. 5 illustrates the force applied on the carbody. The equipment is connected to the chassis by two points according to the practical application. To make the vibration characteristics of system more clear, the carbody is exposed to disturbances at air springs supporting positions and suspended equipment positions. Both the bouncing and pitching movements of carbody and equipment are considered, respectively. The amplitude-frequency characteristics of the carbody and equipment vibration can be obtained by applying a displacement swept excitation $g(t)=A \sin (\omega t)$ at the bottom of air springs, where $A$ is the amplitude, and $\omega$ is the frequency of the applied sine wave. The air springs and rubber elements are mainly molded as parallel spring-damper elements.

According to the coordinate system defined in Fig. 5, the vertical vibration displacement of carbody is represented by $z(x, t)$, in which $x$ is the coordinate from carbody end, and $t$ is the time variable. The bouncing displacement of carbody is $z_{\mathrm{c}}(t)$, and pitching displacement is represented as $\theta_{\mathrm{c}}(t)$. The forces of air springs applied on carbody are represented by $F_{\mathrm{s} 1}$ and $F_{\mathrm{s} 2}$ at positions $x_{1}$ and $x_{2}$, respectively; and the forces of equipment applied on carbody are described as $F_{\mathrm{e} 3}$ and $F_{\mathrm{e} 4}$ at the positions $x_{3}$ and $x_{4}$, respectively.

The appropriate partial differential equation of the carbody movement can be written as [12]

$$
\begin{aligned}
E I & \frac{\partial^{4} z(x, t)}{\partial x^{4}}+\mu I \frac{\partial^{5} z(x, t)}{\partial t \partial x^{4}}+\rho A \frac{\partial^{2} z(x, t)}{\partial t^{2}} \\
& =\sum_{j=1}^{2} F_{\mathrm{s} j} \delta\left(x-x_{j}\right)+\sum_{j=3}^{4} F_{\mathrm{e} j} \delta\left(x-x_{j}\right),
\end{aligned}
$$

where $E I$ represents the flexural rigidity; $\mu I$ represents the structural damping; $\rho A$ is the mass per unit length; and $\delta$ is the daric function; $F_{\mathrm{s} 1}$ and $F_{\mathrm{s} 2}$ are the forces applied by air springs of front and rear bogies, respectively; $F_{\mathrm{e} 3}$ and $F_{\mathrm{e} 4}$ are the forces applied by equipment at front and rear connection, respectively. Here, $F_{\mathrm{s} 1}, F_{\mathrm{s} 2}, F_{\mathrm{e} 3}$, and $F_{\mathrm{e} 4}$ are described as

$$
\begin{aligned}
& F_{\mathrm{s} j}=-k_{\mathrm{s}}\left[z\left(x_{j}, t\right)-g(t)\right]-c_{\mathrm{s}}\left[\dot{z}\left(x_{j}, t\right)-\dot{g}(t)\right], \quad j=1,2, \\
& F_{\mathrm{e} j}=-k_{\mathrm{e}}\left[z\left(x_{j}, t\right)-z_{\mathrm{e}}\right]-c_{\mathrm{e}}\left[\dot{z}\left(x_{j}, t\right)-\dot{z}_{\mathrm{e}}\right], \quad j=3,4
\end{aligned}
$$

The variable separation method is usually used to solve the partial differential Eq. (1). It is assumed that the shape function and modal coordinate of the $i$ th mode of carbody are $Y_{i}(x)$ and $q_{i}(t)$, respectively. When the rigid modes are included with the flexible modes in $z(x, t)$, the bouncing of rigid mode is chosen as the first mode of the carbody, and its shape function is taken as $Y_{1}(x)=1$. The second mode is the pitching, and its shape function is $Y_{2}(x)=x-L / 2$, where $L$ is carbody length. When $n$ modes are considered, the vertical displacement of the carbody can be written as [12]

$z(x, t)=z_{\mathrm{c}}(t)+(x-L / 2) \theta_{c}(t)+\sum_{i=3}^{n} Y_{i}(x) q_{i}(t)$.

By substituting Eq. (4) into Eq. (1) and integrating along the length of carbody, and considering the orthogonality of shape functions and the characteristic of Dirac function, one obtains

$$
\left.\begin{array}{c}
\ddot{q}_{i}(t)+2 \xi_{i} \omega_{i} \dot{q}_{i}(t)+\omega_{i}^{2} q_{i}(t)=\sum_{j=1}^{2} \frac{Y_{i}\left(x_{j}\right)}{M_{\mathrm{c}}} F_{\mathrm{s} j}+\sum_{j=3}^{4} \frac{Y_{i}\left(x_{j}\right)}{M_{\mathrm{c}}} F_{\mathrm{e} j}, \\
M_{\mathrm{c}} \ddot{z}_{\mathrm{c}}(t)=\sum_{j=1}^{2} F_{\mathrm{sj}}+\sum_{j=3}^{4} F_{\mathrm{e} j}, \\
I_{\mathrm{c}} \ddot{\theta}_{\mathrm{c}}(t)=\sum_{j=1}^{2} F_{\mathrm{sj}}(x-L / 2)+\sum_{j=3}^{4} F_{\mathrm{ej}}(x-L / 2),
\end{array}\right\},
$$

where $i=3,4,5, \ldots, n$;

$\frac{E I \beta_{i}^{4}}{\rho A}=\omega_{i}^{2}, \quad \frac{\mu I \beta_{i}^{4}}{\rho A}=2 \xi_{i} \omega_{i}$,

in which $\omega_{i}$ is the $i$ th mode natural frequency of carbody, and $\xi_{i}$ is the $i$ th mode structural damping ratio.

The bouncing $z_{\mathrm{e}}$ and pitching $\theta_{\mathrm{e}}$ movement of equipment can be described as

$$
\left.\begin{array}{l}
m_{\mathrm{e}} \ddot{z}_{\mathrm{e}}=\sum_{j=3}^{4} F_{\mathrm{e} j}, \\
I_{\mathrm{e}} \ddot{\theta}_{\mathrm{e}}=\sum_{j=3}^{4} F_{\mathrm{ej}}\left[x_{i}-\left(x_{3}+x_{4}\right) / 2\right] .
\end{array}\right\} .
$$

If a two-stage vibration isolation system is applied, then the Eq. (7) could be regarded as the vibration equations of the equipment frame, and the bouncing $z_{\mathrm{e} 1}$ and pitching $\theta_{\mathrm{e} 1}$ movement of equipment itself can be described in a similar pattern. 
3.1 Single-stage vibration isolation system analysis

\subsubsection{Dynamic unbalance}

To analyze the effects of dynamic unbalance excitation from equipment on carbody vibration, a $20 \mathrm{~g}$ rotating unbalance in $0.1-100 \mathrm{~Hz}$ frequency range is applied on the equipment in a single-stage isolation system using a sweep frequency excitation method, and the acceleration of carbody center and equipment are analyzed. In this section, single equipment is suspended under the carbody chassis. Two weight cases and several suspension stiffness cases are considered, respectively.

The vibration acceleration of carbody center and equipment are shown in Figs. 6 and 7, respectively, and the vibration transmissibility from equipment to carbody is shown in Fig. 8. One can see that the acceleration of carbody center increases with the equipment suspension stiffness (Fig. 6), but the equipment vibration remains steady (Fig. 7), and both the results of mass 4,000 and $500 \mathrm{~kg}$ cases show a similar pattern. It can be concluded that a rigid connection will transfer more vibration from equipment to carbody. In addition, the carbody vibration resonances locate at the first and third bending modes of carbody, because the center gets the maximum displacements and acceleration for the first- and third-order bending modes of an elastic beam. The structural damping for the third bending mode is quite small, and then a resonance occurs when a swept frequency excitation was applied. Therefore, the dynamic unbalance resonance should be avoided from the flexible modes of carbody. Figure 8 indicates that a small suspension stiffness could decrease the transmission of high frequency vibration, and the carbody vibration would be more satisfying if the excitation frequency was higher than $25 \mathrm{~Hz}$ which is far away from the frequency range where flexible modes concentrated in.
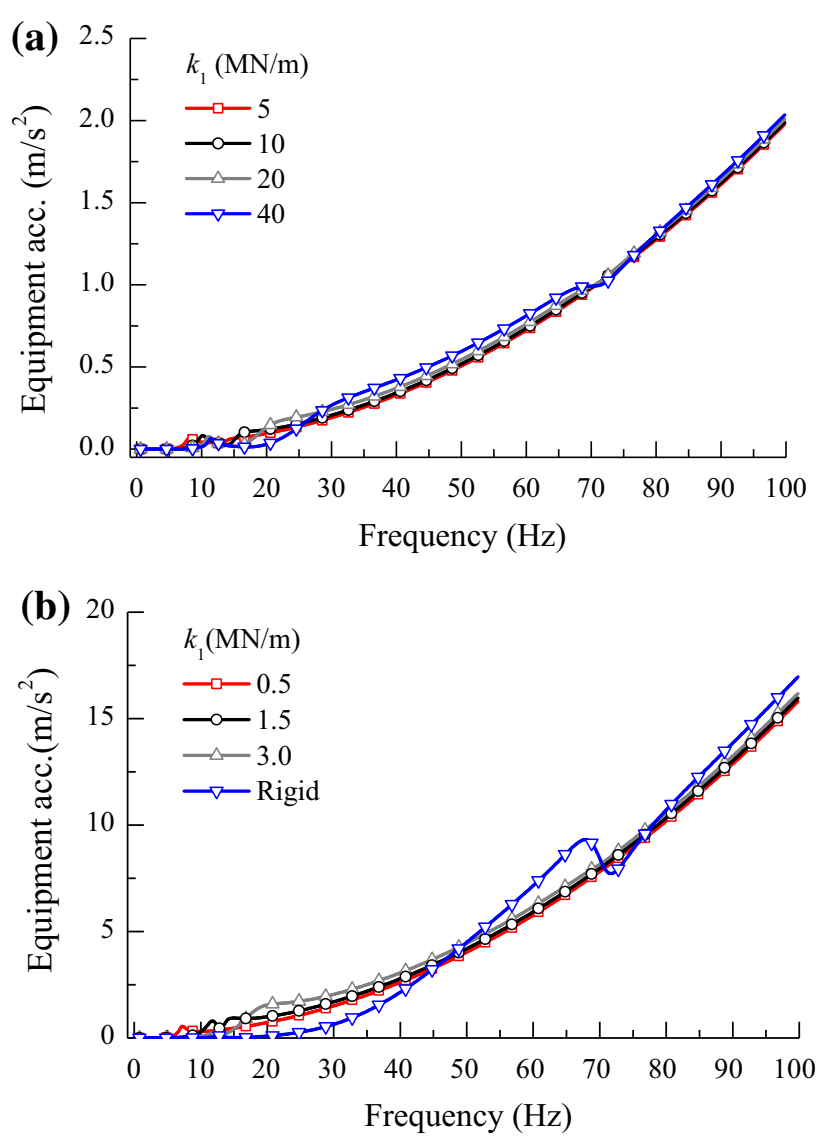

Fig. 7 The vibration acceleration of equipment with different equipment mass: a 4,000 kg; b $500 \mathrm{~kg}$

\subsubsection{Impact turbulence}

To analyze the effects from the impact turbulence of equipment on carbody vibration, half sine waves are used to simulate the impact force. A wave with amplitude of $10 \mathrm{kN}$ lasting for $0.1 \mathrm{~s}$ shown in Fig. 9a is applied with a time period of $1.5 \mathrm{~s}$ based on the engineering practice. The
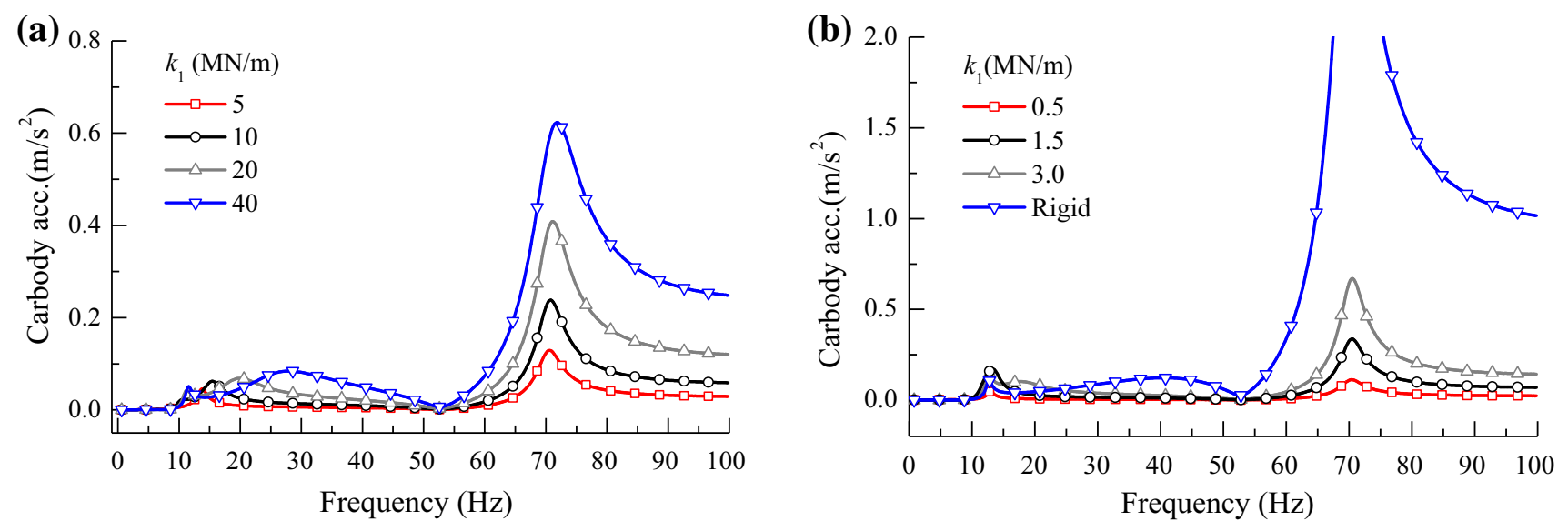

Fig. 6 The vibration acceleration of carbody center with different equipment mass: a 4,000 kg; b $500 \mathrm{~kg}$ 

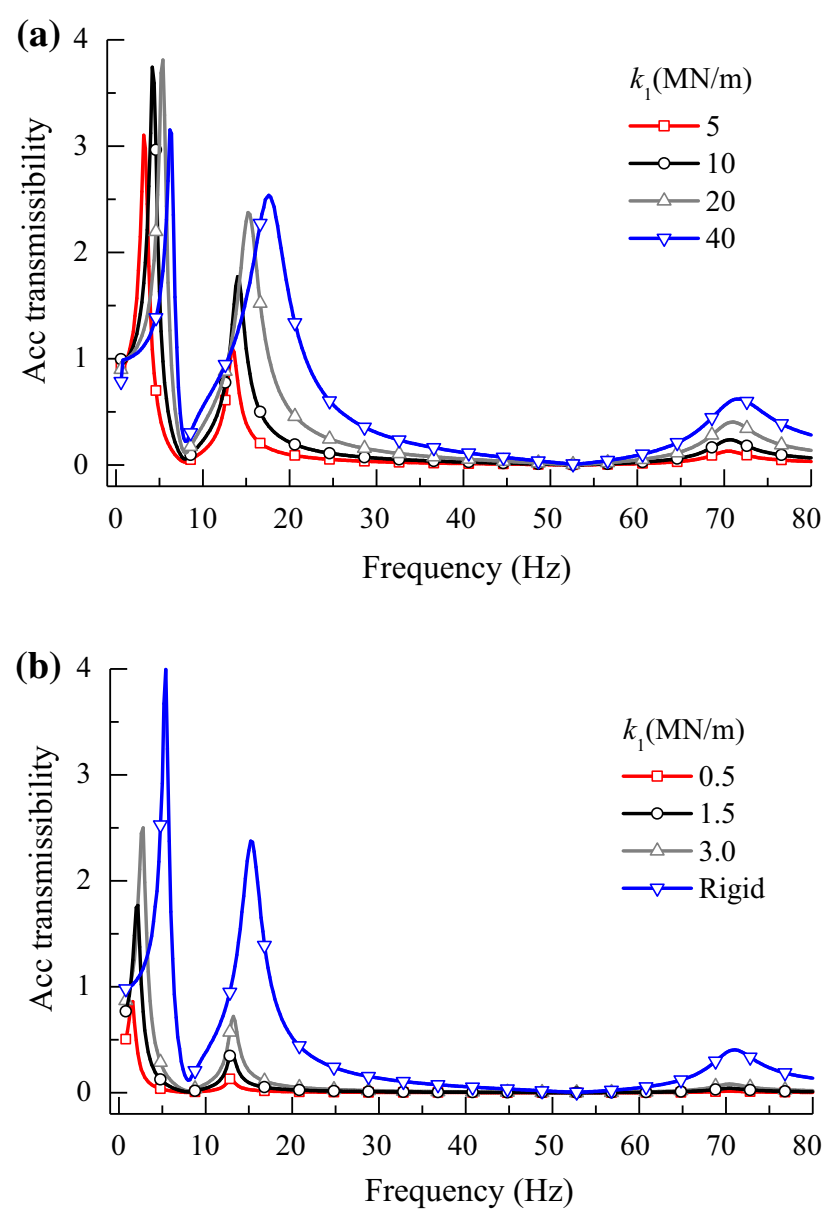

Fig. 8 The acceleration transmissibility of carbody with different equipment mass: a 4,000 kg; b $500 \mathrm{~kg}$

equipment weighs $500 \mathrm{~kg}$. The system vibration is discussed for different suspension stiffness cases, and the results are shown in Figs. 9b and 10.

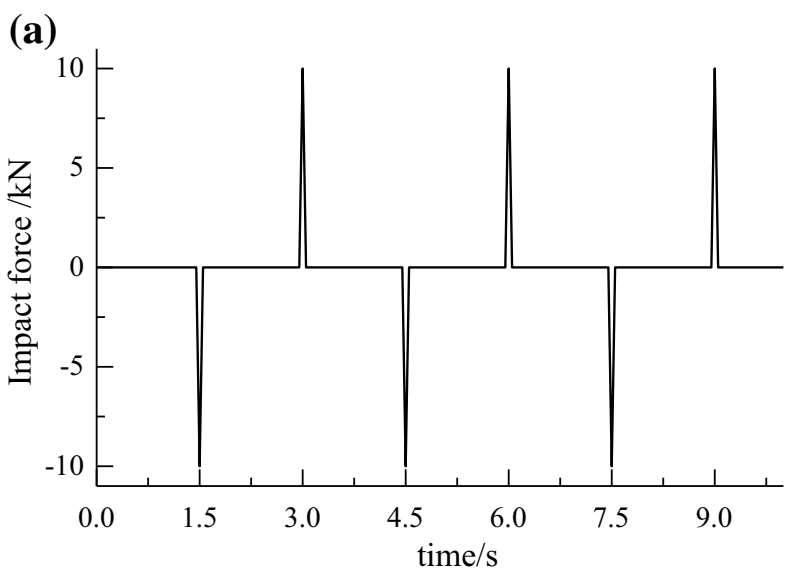

The black curve in Fig. $9 \mathrm{~b}$ shows that the carbody acceleration increases with the equipment suspension stiffness first, but then decreases sharply, and increases again. And the carbody vibration acceleration is the smallest when the equipment is suspended with a quite small stiffness and becomes nearly as large as that in rigid suspension cases when the suspension stiffness increases to a level that the suspension frequency of equipment is close to the frequency of the first bending mode of carbody. For the equipment acceleration, it increases with its suspension stiffness first but then decreases gradually, and it is the smallest in rigid suspension case. Some simulations about equipment weighing $4,000 \mathrm{~kg}$ also show similar vibration characteristics. Therefore, the suspension stiffness of equipment can be optimized to minimize the carbody vibration, and the optimized suspension frequency is a little greater than that of the first bending mode of carbody. Figure 10 shows the time history of carbody acceleration and equipment acceleration, respectively.

\subsection{Two-stage vibration isolation system analysis}

In a two-stage vibration isolation system, the vibration transmission law is more complex. Figure 11 shows the influence of frequency ratio and damping ratio on the vibration transmission in the two-stage isolation case.

Figure 11a gives the acceleration transmissibility in different frequency ratio cases, where $\omega_{n_{-} s}$ represents the second suspension frequency, while the $\omega_{n_{-} p}$ represents the primary suspension frequency [19]. It can be seen that the resonance issue should be considered seriously. In Fig. 11b, when the equipment mass is determined, a small suspension stiffness is suggested.

For the flexible vibration reduction issue of carbody, the transmissions are so implicated that the acceleration

Fig. 9 The system vibration during impact turbulence excitation: a time history of impact turbulence; $\mathbf{b}$ carbody and equipment accelerations at different suspension stiffness $k_{1}$

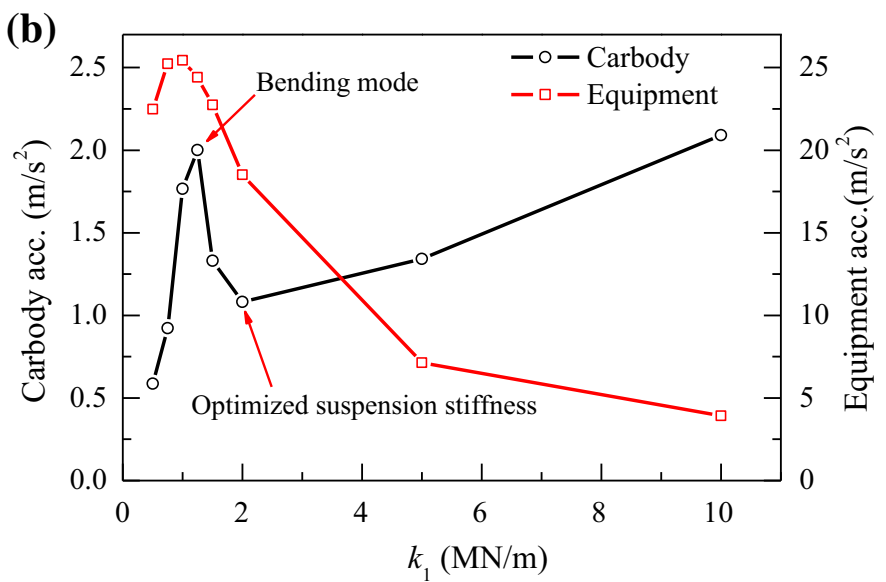
different suspension stiffness $k_{1}$ 
(a)
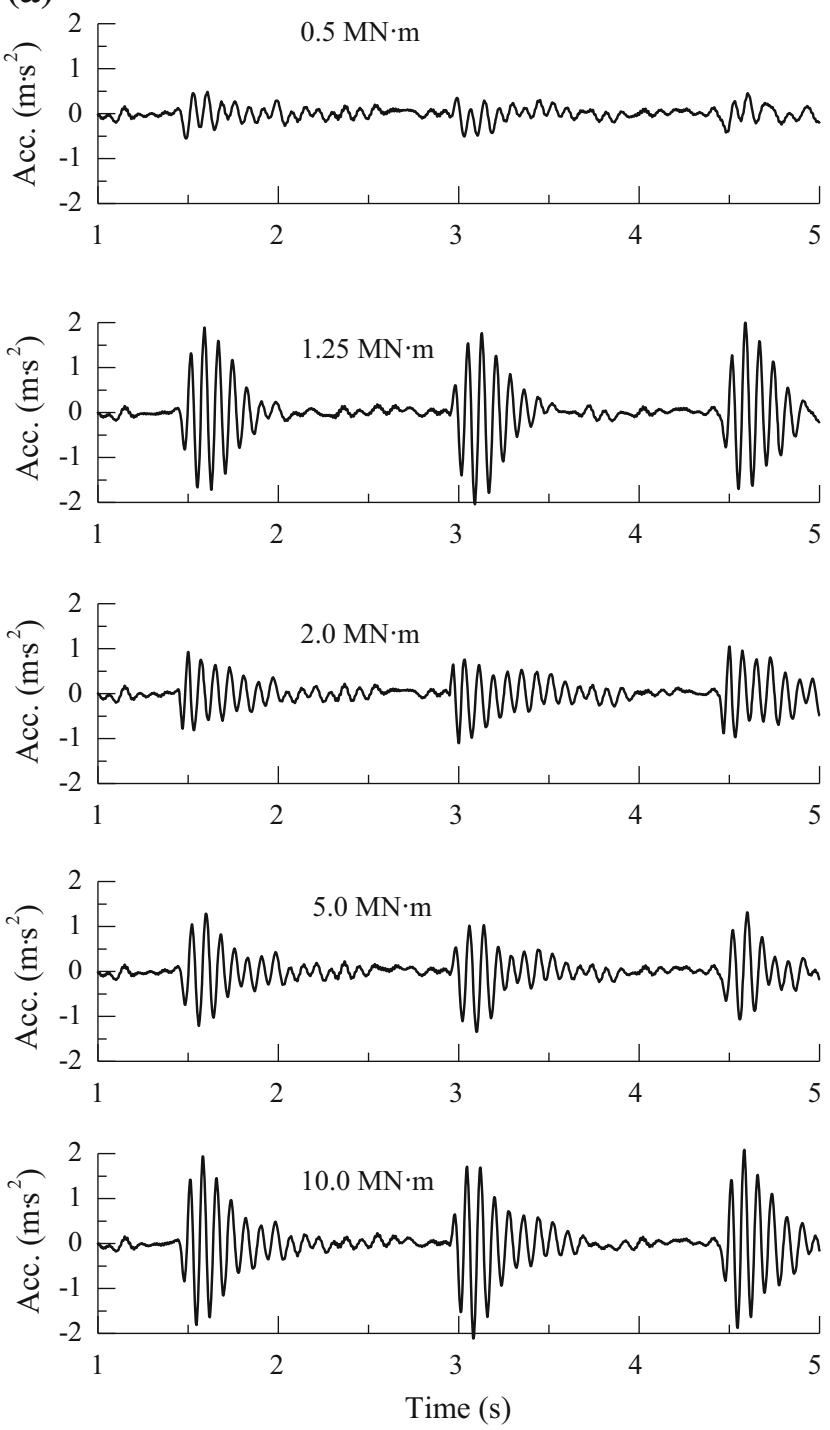

(b)
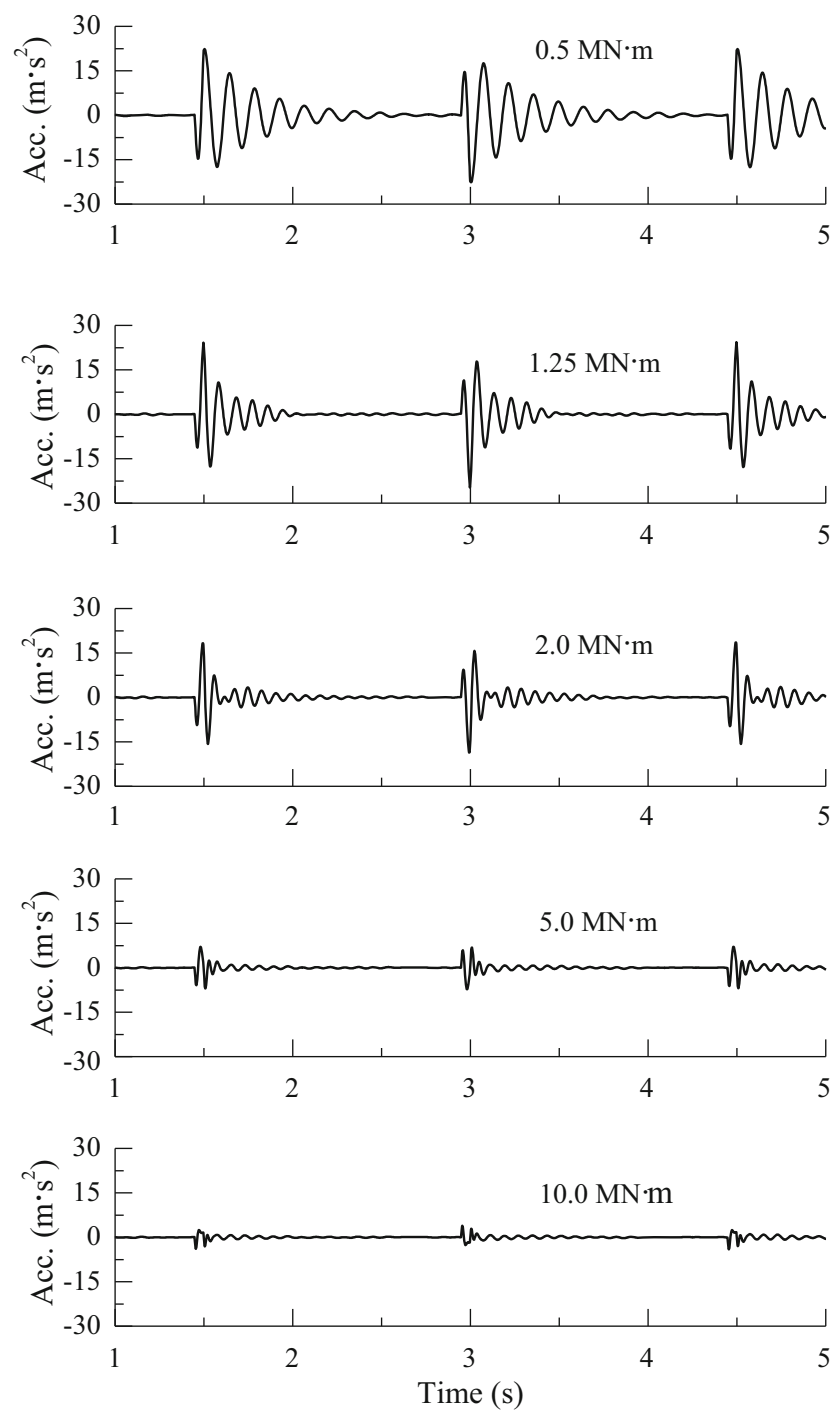

Fig. 10 Time history of vibration acceleration of carbody (a) and equipment (b)

transmissibility could not be obtained easily but the basic law is quite similar. In order to avoid resonance, a small suspension frequency of equipment is preferred to avoid the high frequency vibration transferred to the carbody.

\section{Rigid-flexible coupled multi-body dynamics simulation}

The regular patterns of vibration have been studied using the simplified model in vertical direction in previous sections, then in this section, a 3D rigid-flexible coupled railway vehicle system dynamics model is built based on the MBS theory and the finite element method (FEM) to discuss the vibration of carbody and equipment in the real wheel-rail contact and track excitation condition.
4.1 The railway vehicle system dynamics model including flexible carbody

We built the 3D rigid-flexible coupled dynamics model as shown in Fig. 12 by combing the FEM software ANSYS and MBS dynamics software SIMPACK. The primary suspension is mainly modeled as parallel spring-damper elements, and in the vertical direction, the same type of element has been used to model the vertical bump stop. On the secondary suspension level, the air spring is modeled with parallel spring-damper elements as well, and the yaw damper is built up as a serial spring-damper element considering the stiffness and damping of the rubber mounts. The same element type also characterizes the roll stabilizer bars. Additionally, a lateral stop and a traction link complete the secondary suspension. 

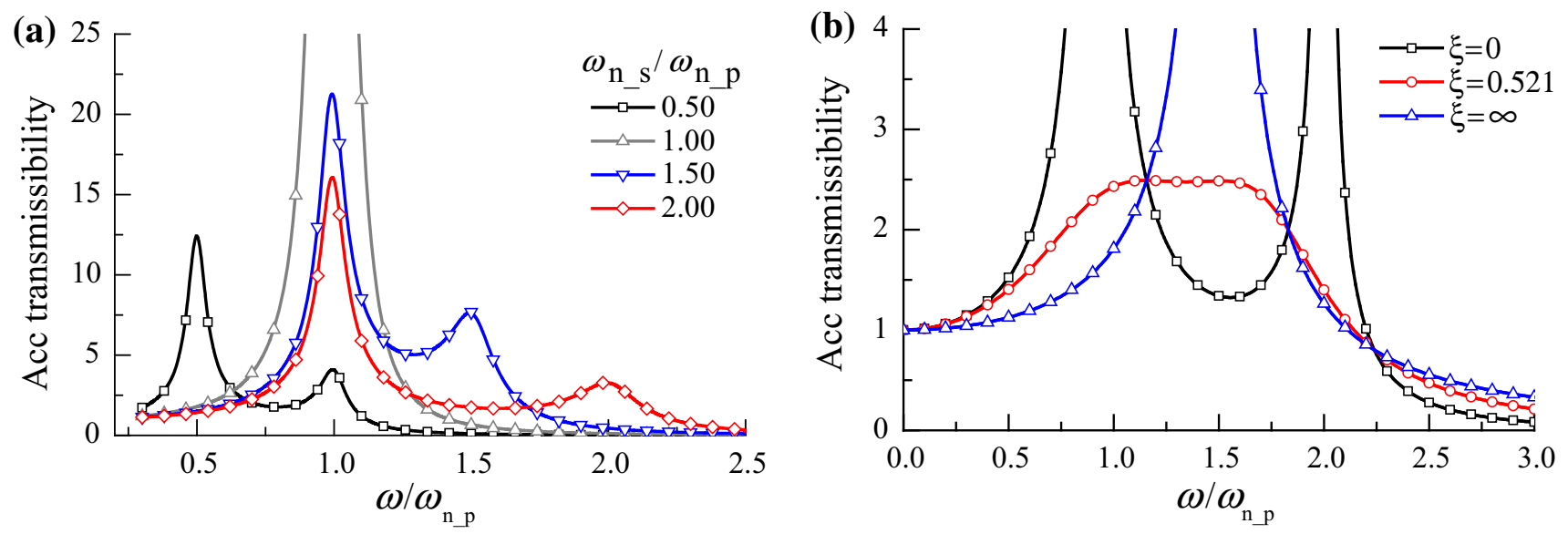

Fig. 11 The acceleration transmissibility of two-stage isolation with different frequency ratios between two stages (a) and different secondary damping ratios $(\mathbf{b})$

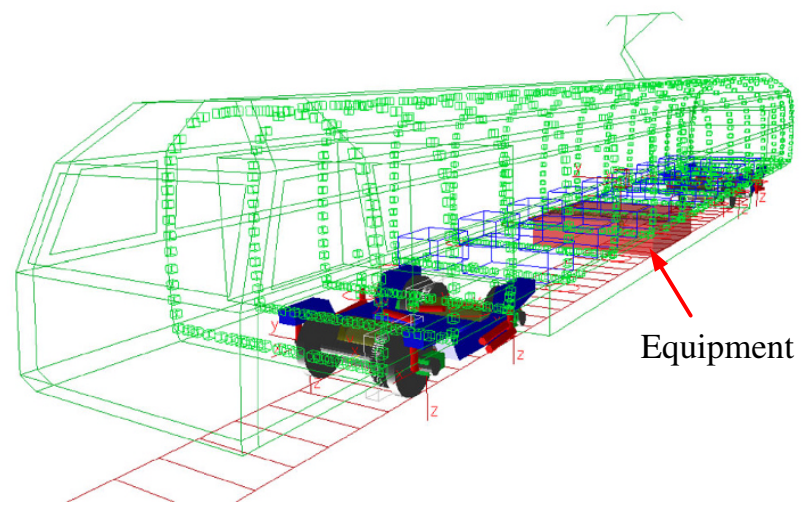

Fig. $123 D$ rigid-flexible coupled dynamics model of EMU

To consider the structural dynamic characteristics of the carbody, it was modeled using the FEM tool. For the integration of the carbody structure into the MBS environment, Guyan method [11] was used to generate a substructure model for the carbody. The modes of the substructure and the original model are listed and compared in Table 2. Several flexible modes are considered in the substructure model, such as the central rhombus mode at $9.67 \mathrm{~Hz}$, vertical bending mode at $12.15 \mathrm{~Hz}$, torsional mode at $11.50 \mathrm{~Hz}$, and the lateral bending mode at $13.46 \mathrm{~Hz}$.

Taking equipment waste collection unit, for example, the mass of equipment frame is $20 \mathrm{~kg}$, and the equipment weighs $120 \mathrm{~kg}$. The equipment is connected to equipment frame elastically with stiffness $k_{1}$, and the frame is suspended under carbody with stiffness $k_{2}$. Both the dynamic unbalance and impact turbulence are considered to study the vibration with and without track irregularity at speed $250 \mathrm{~km} / \mathrm{h}$. Suppose that the static stiffness between frame and carbody is $500 \mathrm{kN} / \mathrm{m}$, and the ratio of dynamic stiffness related to static stiffness is 1.45 .
Table 2 Comparison of flexible modes between the substructure and original model

\begin{tabular}{lccc}
\hline No. & Original $(\mathrm{Hz})$ & Substructure $(\mathrm{Hz})$ & Error $(\%)$ \\
\hline 1 & 9.67 & 9.69 & -0.14 \\
2 & 11.50 & 11.56 & -0.56 \\
3 & 12.15 & 12.18 & -0.17 \\
4 & 13.46 & 13.54 & -0.62 \\
5 & 14.54 & 14.69 & -1.05 \\
6 & 15.75 & 15.81 & -0.41 \\
\hline
\end{tabular}

\subsection{Simulation without track irregularity}

To reflect the vibration transmission law distinctly, the acceleration and suspension force are firstly analyzed without track irregularity excitation.

The relationship between accelerations in different directions and suspension stiffness is shown in Fig. 13. One can see from Fig. 13 that when $k_{1}$ is set to a small value, the lateral vibration of equipment is not the smallest, but the vibration transferred to the hanging frame and carbody is. The vibration is amplified significantly when the suspension stiffness increases to $150 \mathrm{kN} / \mathrm{m}$. This is because that the equipment suspension frequency is close to the carbody flexible mode. Then increasing the suspension stiffness continually, both the equipment and carbody lateral acceleration becomes a little smaller, but a small stiffness is needed to isolate the high frequency vibration as discussed above. The vertical acceleration of equipment decreases with the suspension stiffness. The vertical acceleration of equipment frame increases straightly while that of the carbody increases firstly then decreases.

The influences of suspension stiffness $k_{1}$ on suspension force and frequency are shown in Fig. 14. One can see that 

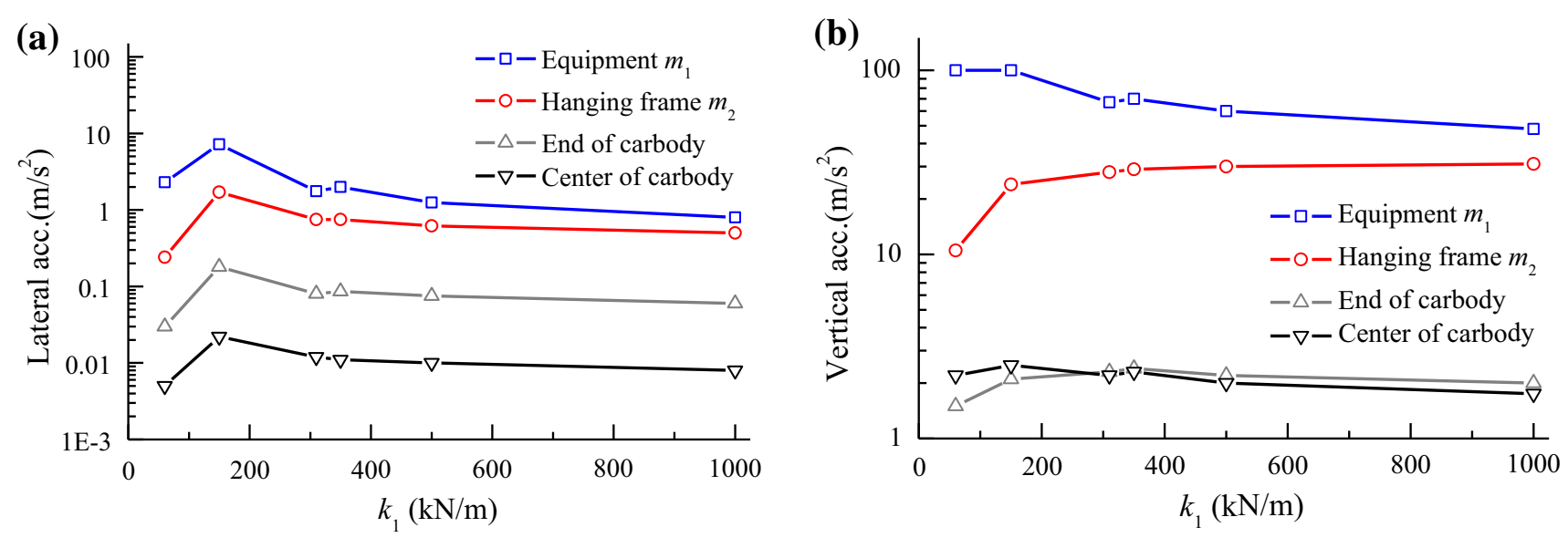

Fig. 13 Relationship between suspension stiffness $k_{1}$ and lateral acceleration (a) or vertical acceleration (b)
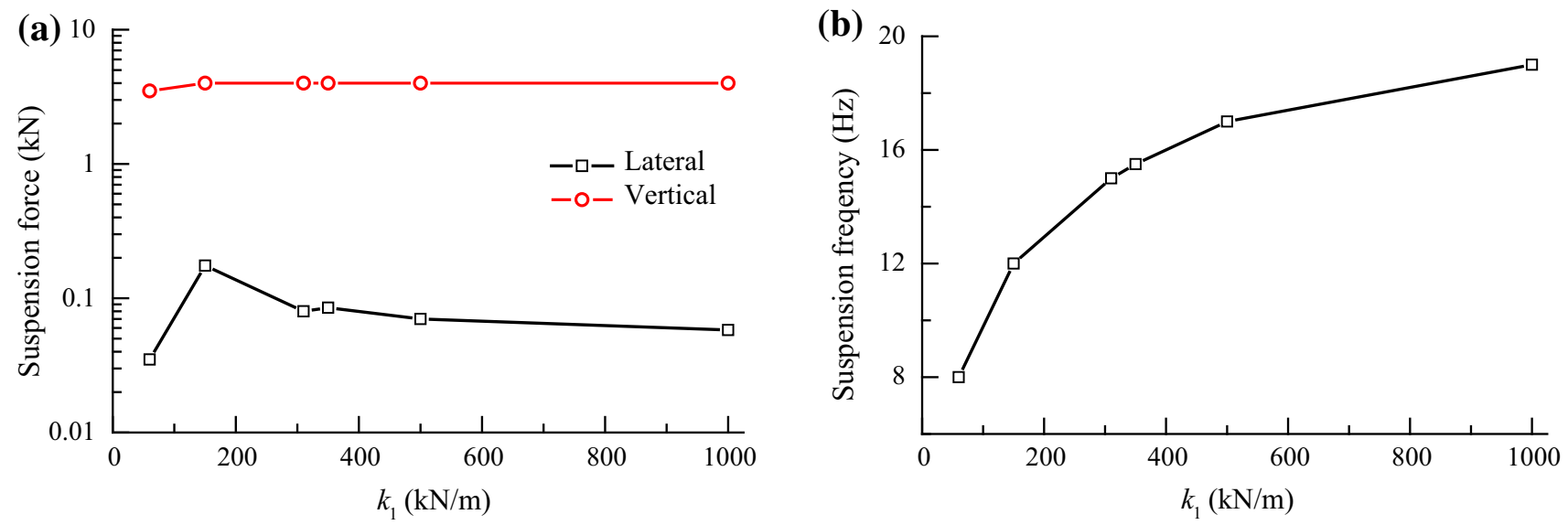

Fig. 14 Relationship between suspension stiffness $k_{1}$ and suspension force (a) or suspension frequency (b)

the lateral suspension force has the same behavior as the lateral vibration (Fig. 14a). The force becomes large when the suspension frequency gets close to the flexible mode. Otherwise, it is much smaller with smaller suspension stiffness and decreases with the increasing of stiffness. When stiffness is big enough and beyond the resonance frequency range, the vertical suspension force changes little.

From Fig. 14b, one can see that the equipment suspension frequency increases with the stiffness; it is $12 \mathrm{~Hz}$ when the vertical stiffness is $150 \mathrm{kN} / \mathrm{m}$, which is close to the first-order bending mode. Thus, the suspension force and vibration acceleration of carbody, frame, and equipment increase sharply. Also, it is $8 \mathrm{~Hz}$ when the vertical stiffness is $60 \mathrm{kN} / \mathrm{m}$; thus, the suspension frequency is smaller than the first-order bending mode of carbody, and a satisfactory vibration isolation performance is obtained. However, a smaller stiffness means a greater static deflection, larger movements, and shorter life cycle of rubber elements. In addition, a greater stiffness is preferred to avoid the resonance.

According to the previous analysis, a great stiffness is better, but the impact turbulence would excite a wide range of frequency response containing the high frequency vibration, which would be transferred to the carbody and affect the riding comforts. Therefore, the suspension stiffness could not be too great and suggested within $300-500 \mathrm{kN} / \mathrm{m}$.

\subsection{Simulation with track irregularity}

The carbody vibration is analyzed in track excitation case with the lateral and longitudinal dynamic unbalance frequency at $25 \mathrm{~Hz}$. Figure 15 shows the time history of carbody vertical acceleration above the equipment with the static suspension stiffness $k_{1}$ from 60 to $1,000 \mathrm{kN} / \mathrm{m}$. The results show that the vertical acceleration increases with the suspension stiffness $k_{1}$, reaches its maximum at 

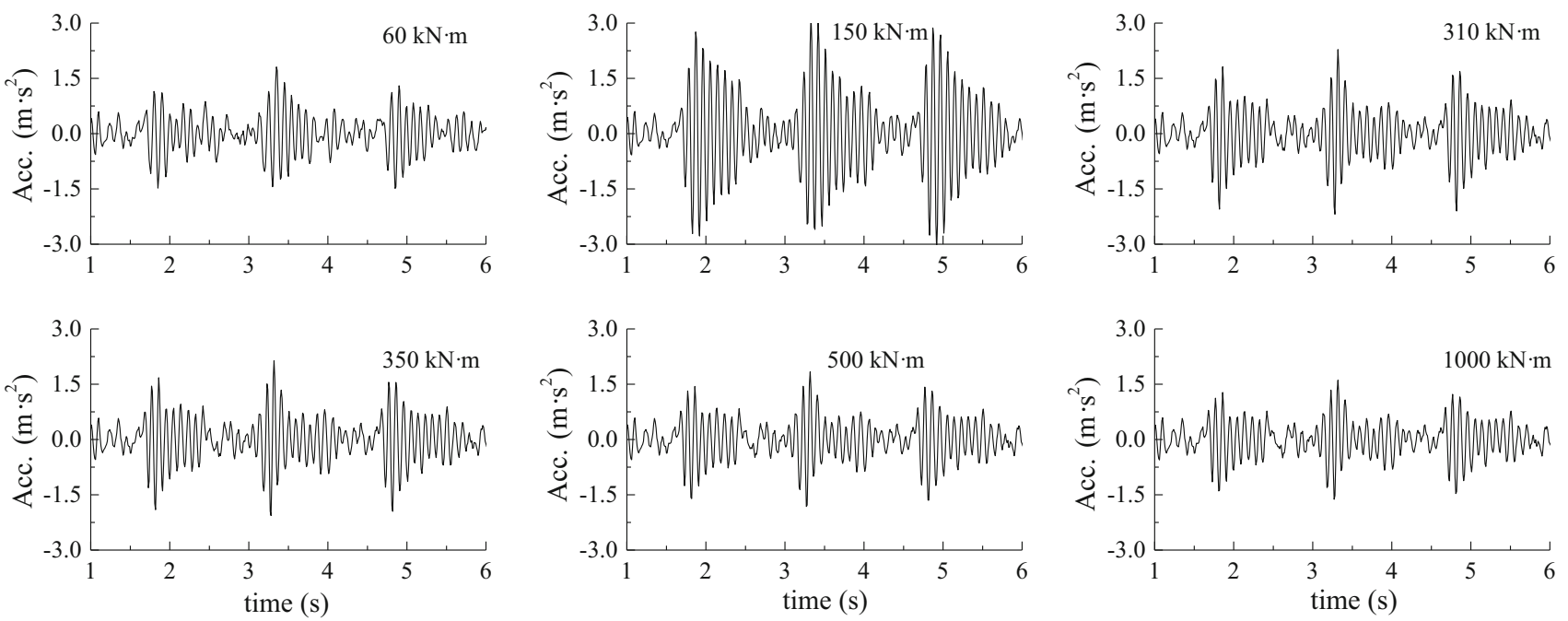

Fig. 15 Time history of vertical acceleration for carbody floor above the equipment
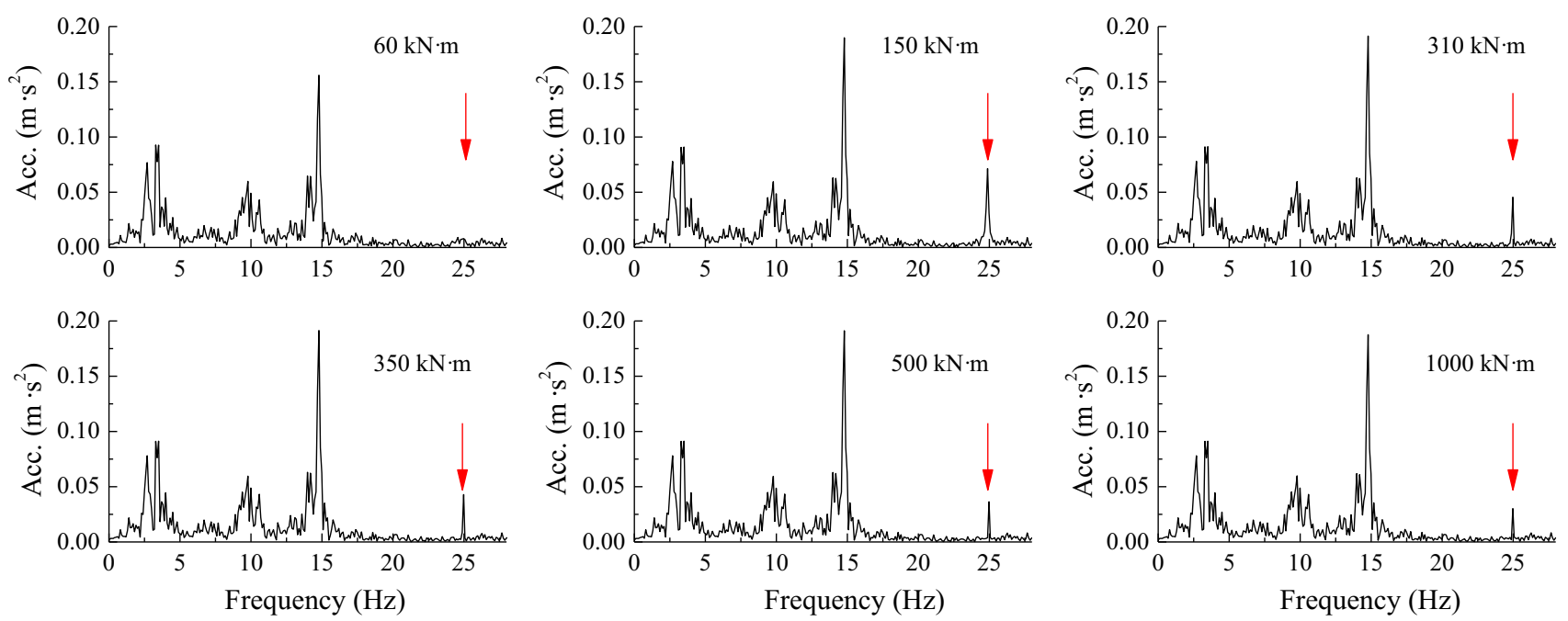

Fig. 16 The frequency spectrum of lateral acceleration of carbody floor above the equipment

$k_{1}=150 \mathrm{kN} / \mathrm{m}$, and then decreases to a constant with $k_{1}$ further increasing.

Figure 16 shows the frequency spectrum of lateral acceleration of carbody. It can be concluded that suspension stiffness has quite limited influence on the flexible vibration of carbody at 10 and $14.5 \mathrm{~Hz}$, because both the equipment and frame mass is much less compared to the carbody mass $\left(m_{1}+m_{2}=140 \mathrm{~kg}\right)$. With the increasing of suspension stiffness, the dynamic vibration energy at $25 \mathrm{~Hz}$ increases firstly, then drops, and comes to a constant finally. Smaller stiffness can significantly reduce the transmission of dynamic unbalance, but bigger stiffness is preferred because of the requirement of static deflection.

\section{Conclusions}

According to the mathematical analysis and vehicle system dynamics simulation, the following conclusions can be drawn:

(1) The equipment excitation including dynamic unbalance and impact turbulence was transferred to the carbody and deteriorated the riding comforts. A twostage vibration isolation system is needed to reduce the excitation transmission.

(2) The carbody vibration increases with the equipment suspension stiffness, but the equipment vibration does not change greatly. The vibration transmission could be reduced by increasing the equipment mass and 
lowering the suspension stiffness. The dynamic unbalance frequency should be far away from the carbody flexible modes, and smaller stiffness should be applied to reduce the impact turbulence. However, a small stiffness results in a large movement of the equipment which is restricted by the static deflection in practice, while a great one will transfer the high frequency vibration.

(3) Simulation of the vehicle dynamic system has verified the mathematical analysis. The excitation transmission can be reduced by reasonable suspension parameters through the two-stage vibration isolation system. A reasonable stiffness is preferred which makes the suspension frequency of equipment a bit greater than the first bending mode of carbody.

Acknowledgments This work was supported by the National Science and Technology Support Program of China (No. 2011 BAG10B01), the National Key Basic Research Program of China (No. 2011CB711100), and the National Science and Technology Support Program of China (No. U1334206), and the New Century Excellent Talents of Ministry of Education funded project (No. NCET-10-0664);

Open Access This article is distributed under the terms of the Creative Commons Attribution License which permits any use, distribution, and reproduction in any medium, provided the original author(s) and the source are credited.

\section{References}

1. Wickens AH (2003) Fundamentals of rail vehicle dynamics. Swets \& Zeitlinger Publishers, Lisse, pp 173-205

2. Iwnicki S (2006) Handbook of railway vehicle dynamics. Taylor \& Francis, London

3. Shabana AA, Sany JR (2001) A survey of rail vehicle track simulations and flexible multibody dynamics. Nonlinear Dyn 26(2):179-212
4. Wu PB, Zeng J, Dai HY (2004) Dynamic response analysis of railway passenger car with flexible carbody model based on the semi-active suspension. Veh Syst Dyn 41(S1):774-783

5. Diana G, Cheli F, Bruni S, Collina A (1995) Dynamic interaction between rail vehicle and track for high speed train. Veh Syst Dyn 24(S1):987-997

6. Young TH, Li CY (2003) Vertical vibration analysis of vehicle/ imperfect track systems. Veh Syst Dyn 40(5):329-349

7. Carlbom PF (2001) Combining MBS with FEM for rail vehicle dynamics analysis. Multi-body Syst Dyn 6(3):291-300

8. Schandl G, Lugner P, Benatzky C, Kozek M, Stribersky A (2007) Comfort enhancement by an active vibration reduction system for a flexible railway carbody. Veh Syst Dyn 45(9):835-847

9. Foo E, Goodall RM (2000) Active suspension control of flexiblebodied railway vehicle using electro hydraulic and electromagnetic actuators. Control Eng Pract 8(5):507-518

10. Holst C (1998) Active damping of carbody vibrations. Royal Institute of Technology, Stockholm 877-880

11. Wu HC, Wu PB, Zeng J, Wu N, Shan YL (2012) Influence of equipment under car on carbody vibration. J Traffic Trans Eng 12(5):50-56

12. Shi HL, Luo R, Wu PB, Zeng J, Guo JY (2014) Application of DVA theory in vibration reduction of carbody with suspended equipment for high-speed EMU. Sci China Tech Sci 57(7):1425-1438

13. Shi HL, Wu PB, Luo R (2014) Coupled vibration characteristics of flexible car body and equipment of EMU. J Southwest Jiaotong Univ 49(4):693-699

14. Shi HL, Luo R, Wu PB, Zeng J (2014) Suspension parameters designing of equipment for electric multiple units based on dynamic vibration absorber theory. J Mech Eng 50(14):155-161

15. Snowdon JC (1966) Vibration of cantilever beams to which dynamic absorbers are attached. J Acoust Soc Am 39(5):878-886

16. Jacquot RG (2001) Suppression of random vibration in plates using vibration absorbers. J Sound Vib 248(4):585-596

17. Jacquot RG (2004) Optimal damper location for randomly forced cantilever beams. J Sound Vib 269(3):623-632

18. Thompson DJ (2008) A continuous damped vibration absorber to reduce broad-band wave propagation in beams. J Sound Vib 311(3):824-842

19. Yang C, Li D, Cheng L (2011) Dynamic vibration absorbers for vibration control within a frequency band. J Sound Vib 330(8):1582-1598 